Preface

\section{Disease-Specific Thrombosis}

\author{
Marcel Levi, MD, PhD ${ }^{1}$ \\ ${ }^{1}$ Department of Medicine, Academic Medical Centre, University of \\ Amsterdam, Amsterdam, The Netherlands
}

Semin Thromb Hemost 2013;39:459-460.

Arterial and venous thromboembolisms are frequently occurring disorders and are responsible for a sizeable part of morbidity and mortality throughout the world. Dependent on localization, extent, and specific circumstances, the clinical manifestation and consequences of thrombosis may vary widely. Thrombosis may be due to or associated with specific clinical situations and that is the focus of this issue of Seminars in Thrombosis \& Hemostasis. Disease-specific thrombosis refers to thrombotic complications that occur in the setting of a particular disease. In a series of contributions to this issue of the journal, the epidemiology, specific pathogenesis, special features, and consequences for clinical management of thrombosis in the setting of these diseases are extensively discussed.

Koutroumpakis et al review the incidence of thrombosis in patients with inflammatory bowel disease (including Crohn disease and ulcerative colitis), and they also discuss risk factors and issues pertaining to prevention and treatment of thrombosis in this setting. ${ }^{1}$ Inflammatory bowel disease is another example of the link between inflammatory processes and activation of coagulation, as has been demonstrated in alternative settings as well. ${ }^{2,3}$ In the article by Barbano et al, thrombosis in nephrotic syndrome is reviewed. ${ }^{4}$ They show that in nephrotic syndrome the breakdown of the selectivity barrier of the glomerular capillary wall, resulting in the leakage of high-molecular-mass proteins, contributes to a prothrombotic state. This hypercoagulable condition is supported by several factors, such as abnormalities in platelet activation and an imbalance between anticoagulation/antithrombosis and procoagulant/ prothrombotic mechanisms.

Another example of the disease state that is associated with thrombosis is diabetes mellitus. Obviously, many complications of diabetes are caused by (accelerated) vascular atherosclerosis, but in addition, hypercoagulability and thrombosis may also occur. Pathways underlying this complication are illustrated by Morel et al. ${ }^{5}$ They conclude that targeting the tissue factor-microparticle pathway may be a good approach for reducing the burden of the atherothrombotic complications of diabetes.
Address for correspondence Marcel Levi, MD, PhD, Department of Medicine, Academic Medical Centre E-2, Meibergdreef 9, $1105 \mathrm{AZ}$ Amsterdam, The Netherlands (e-mail: m.m.levi@amc.uva.nl).
Endocrine diseases other than diabetes have also been associated with thromboembolic complications and are discussed by van Zaane et al. ${ }^{6}$ Examples of such endocrine diseases include thyroid diseases, cortisol excess and deficiency, pheochromocytoma, hyperparathyroidism, hyperaldosteronism, hyperprolactinemia, and growth hormone excess and deficiency. The clinical relevance of the changes in the coagulation system caused by these endocrinopathies is not always clear; however, because these diseases frequently occur and thrombotic complications are not rare in these settings, it is likely that these endocrine disease states and thrombosis are indeed linked.

A whole new area of intensive research has recently focused on the role of the JAK2 mutation and the development of thrombosis. Indeed, this mutation has been strongly associated with chronic myeloproliferative diseases, such as essential thrombocythemia and myelofibrosis, which are known to be linked with serious thrombotic complications, often at unusual sites (such as portal vein thrombosis). The article by Vannucchi and Guglielmelli provides an up-to-date ing on the relationship between malignancy and thrombosis, Lauw et al present an overview on the link between cancer and venous thrombosis. ${ }^{8}$ Trousseau ${ }^{9}$ was the first to describe the propensity to thrombosis of patients with cancer centuries ago, but recently, important advancements in our knowledge on this association have been made, both concerning the underlying pathogenetic pathways as well as regarding clinical management. ${ }^{10}$

Lippi et al discuss the relationship between HMG-CoA (3-hydroxy-3-methylglutaryl-coenzyme A) reductase inhibitors (statins) and thrombosis. ${ }^{11}$ Several lines of evidence suggest that the pleiotropic effects of statins may play a role in prevention of venous thrombosis, wherein hypercholesterolemic patients are characterized by enhanced thrombin generation, more susceptibility to endothelial dysfunction and platelet hyperreactivity, so that limiting or counteracting the burden of one or more of these mechanisms would provide an effective means of prophylaxis. This notion seems to be supported by several recent clinical observations.
Copyright @ 2013 by Thieme Medical Publishers, Inc., 333 Seventh Avenue, New York, NY 10001, USA. Tel: +1(212) 584-4662.
DOI http://dx.doi.org/

10.1055/s-0033-1346997. ISSN 0094-6176. and comprehensive review on this subject. ${ }^{7}$ Further elaborat-
Thrombosis; Guest Editor,

Marcel Levi, MD, PhD 
Similarly, large epidemiological studies indicate that obesity is a risk factor for thrombosis. This association is further elaborated in the article by Braekkan et al. ${ }^{12}$ In this article, the authors also discuss how individual components that define obesity can serve as potential biological mechanisms for the observed association between obesity and venous thrombosis.

The increased risk of thrombosis after traumatic injury is known for many years. However, traumatic brain injury seems to provide a particularly high propensity of thrombotic complications, as discussed by Phelan. ${ }^{13}$ In particular, the issue of pharmacological prevention of thrombosis in this setting is extensively reviewed.

Barco et al provide the latest insights into the current knowledge on pregnancy and thromboembolic complications. ${ }^{14}$ Despite major progress in this area, the authors identify a need for methodologically solid studies on pregnant women, especially concerning risk stratification, optimal anticoagulant treatment and monitoring, and its correlation with clinical outcomes and a correct management of anticoagulation during delivery. Finally, Levi et al discuss pathogenesis, risk factors, treatment and prevention of thrombotic complications during severe infection and sepsis. ${ }^{15}$

Taken together, this issue of Seminars in Thrombosis $\mathcal{E}$ Hemostasis provides a wide-ranging overview on specific disease settings in which thromboembolism is a frequent complication. Much knowledge in the pathogenetic pathways underlying the development of thrombosis in these different areas has been accumulated recently and is currently being translated into effective and safe diagnostic and therapeutic modalities that will improve the clinical management of thrombosis as a complication of many diseases.

\section{References}

1 Koutroumpakis EI, Tsiolakidou G, Koutroubakis IE. Risk of venous thromboembolism in patients with inflammatory bowel disease. Semin Thromb Hemost 2013;39(5):461-468

2 Bisoendial RJ, Levi M, Tak PP, Stroes ES. The prothrombotic state in rheumatoid arthritis: an additive risk factor for adverse cardiovascular events. Semin Thromb Hemost 2010;36(4):452-457

3 Levi M, van der Poll T, Schultz M. New insights into pathways that determine the link between infection and thrombosis. Neth J Med 2012;70(3):114-120

4 Barbano B, Gigante A, Amoroso A, Cianci R. Thrombosis in nephrotic syndrome. Semin Thromb Hemost 2013;39(5):469-476

5 Morel O, Jesel L, Abbas M, Morel N. Prothrombotic changes in diabetes mellitus. Semin Thromb Hemost 2013;39(5):477-488

6 van Zaane B, Stuijver DJF, Squizzato A, Gerdes VEA. Arterial and venous thrombosis in endocrine diseases. Semin Thromb Hemost 2013;39(5):489-495

7 Vannucchi AM, Guglielmelli P. JAK2 mutation-related disease and thrombosis. Semin Thromb Hemost 2013;39(5):496-506

8 Lauw MN, van Doormaal FF, Middeldorp S, Buller HR. Cancer and venous thrombosis: current comprehensions and future perspectives. Semin Thromb Hemost 2013;39(5):507-514

9 Trousseau A. Phlegmasia alba dolens. Clin Med Hotel Dieu Paris 1865;3:3695

10 Levi M. Cancer and thrombosis. Clin Adv Hematol Oncol 2003; 1(11):668-671

11 Lippi G, Favaloro EJ, Sanchis-Gomar F. Venous thrombosis associated with HMG-CoA reductase inhibitors. Semin Thromb Hemost 2013;39(5):515-532

12 Braekkan SK, Siegerink B, Lijfering WM, Hansen JB, Cannegieter SC, Rosendaal FR. Role of obesity in the etiology of deep vein thrombosis and pulmonary embolism: current epidemiological insights. Semin Thromb Hemost 2013;39(5):533-540

13 Phelan HA. Venous thromboembolism after traumatic brain injury. Semin Thromb Hemost 2013;39(5):541-548

14 Barco S, Nijkeuter M, Middeldorp S. Pregnancy and venous thromboembolism. Semin Thromb Hemost 2013;39(5):549-558

15 Levi M, Schultz M, van der Poll T. Sepsis and thrombosis. Semin Thromb Hemost 2013;39(5):559-566 